ide - of a strength not greater than $50 \%$ - I presume would be a more rational and equally useful application.

\section{$A$ BRIEF SUMMARY OF NINE CASES OF LOBAR PNEUMONIA TREATED BY ICE PACK.}

BY GEORGE L. COLLINS, M. D.,

House Officer, Carney Hospital.

Having in mind the discussion of the treatment of pneumonia in the Medical Communications of the Massachusetts Medical Society, Vol. XVIII, it was deemed advisable in the last service of Dr. Wm. F. Temple, at the Carney Hospital, to try the effect of treatment of lobar pneumonia by the continued application of dry cold over the seat of the pulmonary lesion. The cases reported below came under my direct charge during this service. The treatment adopted consisted in the conventional supportive and symptomatic treatment plus the application of dry cold by means of ice-bags.

CASE I. M. H., age sixty-five. Comes in with temperature of $102^{\circ}$, pulse 100 , respirations 40 . Second day of attack : Pain in left lower chest; cough. Bronchial breathing, prolonged expiration and few fine crepitant râles at left base. Lungs otherwise negative. White count, 21,000 . Treatment: Liquid diet, whiskey half ounce every three hours; strychnia, one-sixtieth grain every four hours. Left chest packed with ice-bags below. In one day temperature reached 103.6, and two days later (fifth day of disease) the temperature, pulse and respirations were normal. Signs in chest never showed any increase; never any dullness. Râles cleared up on fifteenth day. This patient was the only one of 9 cases to complain of discomfort of ice-bags. Discharged well on 18th day of disease.

CASE II. C. F., age twenty-three. Comes in on second day of attack. Cough; pain in neck, chest and abdomen, bloody sputum, anorexia, vomiting. Heart enlarged, no murmurs, pulse regular. Expansion of chest limited on left side; left lower lobe shows usual signs of consolidation; only few râles in right chest. Temperature $103^{\circ}$, pulse 120 , respirations 46 ; white count 52,000 ; urine normal. Treatment: Strychnia, rum, ice pack to left chest. Two days later (fourth day of attack) temperature fell to $99.2^{\circ}$, reached normal a week later. Ice pack omitted on eleventh day of attack. Signs cleared up on fifteenth day. (See diagram.)

CASE III. M. S., age sixteen. Entered on third day of attack. Headache; pain in chest, aggravated by cough and deep inspiration. No expectoration of any account. On entrance nothing found in chest but weak breathing in lower left chest ; face flushed, temperature $102.3^{\circ}$; white count 46,000 ; urine normal with chlorides diminished. Left chest packed with ice about the base on the chances. 'Two days later (fifth day of attack) distinct and marked signs of consolidation in upper right lobe. Temperature on this day $103^{\circ}$. Ice pack at once changed to this side, and rum and strychnia continued as from entrance. Temperature dropped on this day. Reached normal on eighth day of disease. On thirteenth day of attack dullness almost all cleared up; râles on coughing; slight pleuritic pain in lower right chest. Signs cleared up on seventeenth day. (See diagram.)

CASE IV. M. M., age seven. Entered on third day of attack. Temperature $104^{\circ}$, pulse 130 , respirations 40. Pain in left chest, cough; no expectoration, headache, anorexia, constipation, some abdominal pain. Usual signs of dullness, with no râles in left lower lobe. White count, 50,000. Active hyperemia of kidney. Treatment: Whiskey, liquids, strychnia, left lower chest packed in ice. One day later (fourth day of disease) temperature began to fall, and was normal on sixth day. Signs cleared up on fourteenth day.

CASE V. D. M., age sixty. Entered on second day of attack. Cough ; dyspnea ; slight expectoration, not bloody; constipated; pain in chest; cheeks flushed; white count 10,000 ; temperature $101^{\circ}$. Treatment: Whiskey, strychnia, ice pack to left chest, where dullness with bronchial breathing and râles were found. Three days later distinct consolidation of right middle lobe with usual signs appeared, with friction rub over lower right lobe. White count 13,000. Left chest now clear. Ice pack changed to right side of chest. Pulse now intermittent. Temperature still about $101^{\circ}$. Two days later (seventh day of attack) temperature rose to $102^{\circ}$, pulse 100 , irregular and intermittent, respirations 50. One day later, signs remaining unchanged, patient died.

CASE VI. M. M., age 28. Entered on third day of attack. Chill ; pain in right side of chest; vomiting, expectoration greenish; pain made worse by cough and deep inspiration; constipated; now menstruating. Dullness with usual signs over right upper lobe, râles throughout either chest, - moist and bubbling. Question arose whether we were dealing with a pneumonia in state of resolution, or a pneumonia on top of a generalized bronchitis. Ice pack decided on ; rum, strychnia. White count 52,000; active hyperemia of kidneys; pneumococci in sputa. Temperature $103.5^{\circ}$, pulse 120 ; respirations 58 . In three days (sixth day of disease) temperature fell to normal, and process in right upper lobe cleared up on tenth day. Râles in either chest persisted until discharge of patient. This patient was exceptionally sick on entrance and for three days after entrance, but she never complained of inconvenience from ice pack. Ice pack was left on six days and removed on ninth day of attack.

CASE VII. C. H., age thirty-eight. Comes in in state of delirium tremens. On spree four days. Dullness with usual signs found in lower left lobe. As near as can be made out this is fourth day of attack. Dyspnea, cough ; pain in lower left chest, made worse by cough or deep inspiration. No blood in expectoration. Temperature $103^{\circ}$; white count 17,300. Treatment: Calomel, followed by salts; bromides, chloral, capsicum; ice bags to 
left lower chest, whiskey, strychnia. In twenty-/fell on fifth day of attack. Lungs showed only four hours temperature fell to about normal (fifth an occasional râle on ninth day. day of attack). Signs in chest practically all gone on twentieth day.

SUMMARY AND CONCLUSIONS.

Case VIII. G. S., age eleven. Entered on In only one case did the ice pack cause discomsecond day of attack. No chill; cough, pain in fort. In no case was the crisis accompanied by right chest, no expectoration; dullness with usual dangerous collapse.

signs over right upper lobe. Chlorides in urine The pack has been used to abort cases just bediminished; white count 23,000 ; temperature $105^{\circ}$; ginning (Case I), in cases with well marked signs, pulse 123, of poor volume and compressible; res- and in cases showing resolution.

pirations 50. Treatment: Rum, strychnia, ice Contemporary signs of bronchitis were not conpack to affected lobe. In three days (fourth day $\mid$ sidered contra-indicatory.

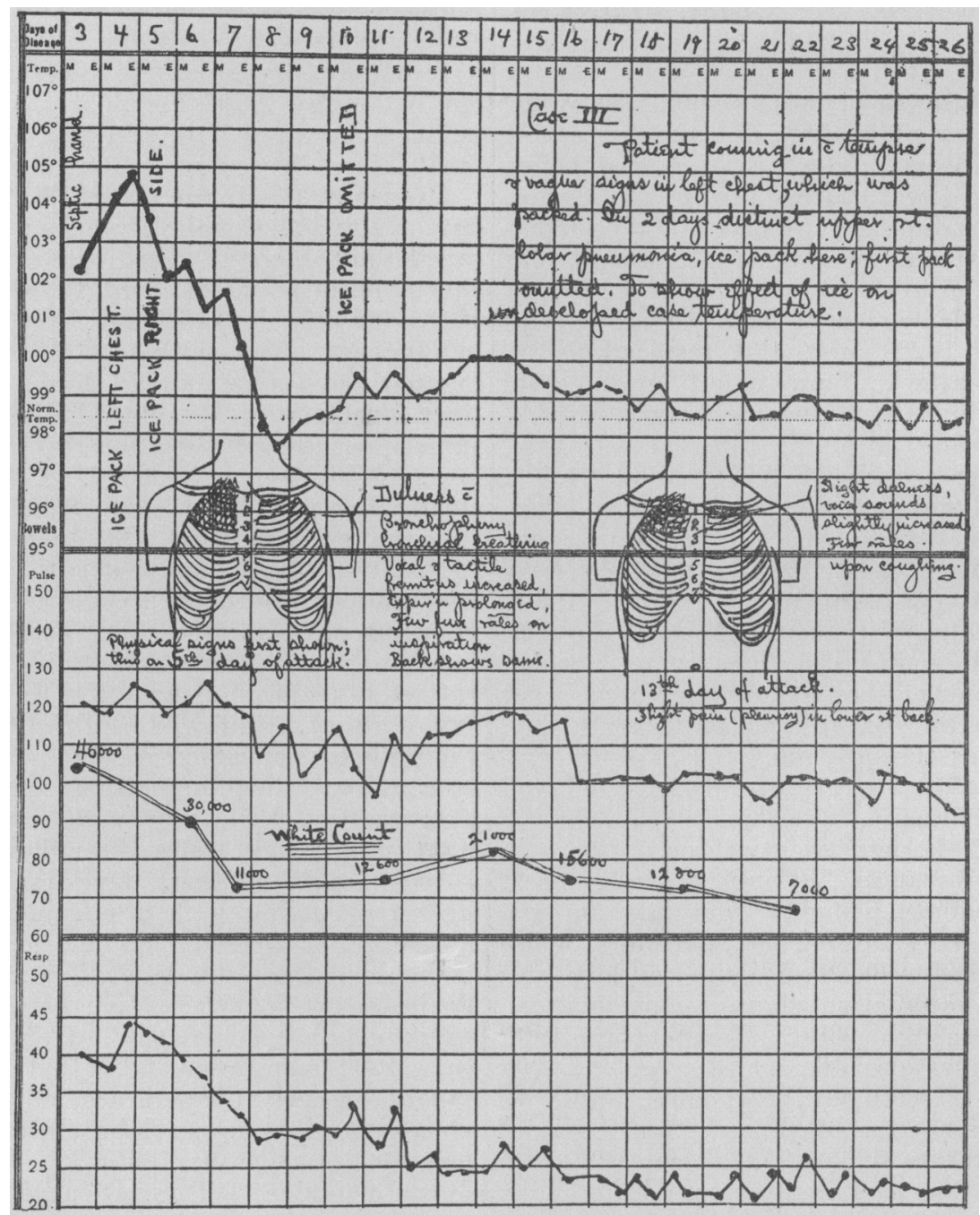

of attack) temperature dropped to normal, and white count dropped to 16,600 . On sixth day ice omitted. Signs cleared up by fourteenth day.

CASE IX. G. B., age fourteen. Entered on been in each case the indication for removal third day of attack. Pain in right back, vomit- of ice. The average fall in temperature was $4.5^{\circ}$. ing, cough; pain made worse by cough; rusty In all but one case this fall was within forty-eight expectoration. Temperature $103^{\circ}$, pulse 110 , res- hours of application of ice. In most cases it was piration 30. Physical examination shows dullness within twenty-four hours. The slowest fall of with usual signs over middle lobe, especially in temperature following ice pack was in Case III, back. White count 34,400. Treatment: Rum, when temperature took five days to fall $7^{\circ}$. This strychnia, ice pack to right chest. Temperature patient was suffering from a septic hand. The 
average fall of temperature was $4.5^{\circ}$ and took place on the fourth day.

The white count invariably began to fall with the temperature, but reached normal in no less than one week after temperature was normal.

The ice pack apparently had no particular effect in either shortening or prolonging the duration of physical signs. The physical signs cleared up on the fourteenth day.

\section{Medital Brogregg.}

\section{RECENT PROGRESS IN PUBLIC HYGIENE.} BY SAMUEL W. ABBO'T, M.D., Boston.

THE MANAGEMENT AND CONTROL OF INFECTIOUS DISEASES.

\section{The Utility of Isolation Hospitals in Diminish- ing the Spread of Scarlet Fever.}

Atrempts having been made in England to show that isolation hospitals had failed to accomplish the object for which they were intended, Dr. Newsholme ${ }^{1}$ contributes a paper in which he shows that, if death rates are to be considered as conclusive, the returns relating to scarlatina "show a strong case for the continued use of the present preventive measures, among which hospital isolation and disinfection claim an important part." He shows that in the period 1850 to 1885 the death rate had been extremely irregular, rising frequently to a very high rate and then sinking to a very low one, as, for example, from 451 per million in 1861 to 1478 per million in 1863 , and down again to 546 in 1866 . But since 1885 the mean rate had not only been low, but it had been quite uniform and free from extremes from that time to the present. He concludes that " preventive measures, among which hospital isolation holds an important place, have been associated with the remarkable and almost uninterrupted decline in the death rate from this disease."

The reasons which he assigns for the fact that an ideal condition has not yet been attained are briefly the following :

(1) Hospital and home isolation have never been perfectly carried out.

(2) Not only have a considerable proportion of the notified cases remained unisolated, but a considerable proportion of the total cases have not been notified. This is due to various causes, such as failure to call in medical aid in slight or unrecognized cases, errors in diagnosis and neglect to notify. Every additional case notified gives an additional opportunity for preventing the spread of the disease by personal infection; and every such notified case can be made a centre of inquiry leading to the detection of unnotified cases, if sanitary administration be active and intelligent.

(3) The best sanitary administration cannot accomplish everything. There must be hearty co-operation on the part of parents and med-

\footnotetext{
1 Journal of Hygiene, vol. i, No. 1, p. 145, January, 1901.
}

ical practitioners, if efforts to secure early diagnosis and early isolation are to be successful. The law is much more regardful of the welfare of cattle than of human beings. A doctor is not required to notify a case of scarlet fever till he " becomes aware" that it is certainly of this nature, but a farmer must notify each case, and each suspected case of certain cattle diseases.

To suppose that the spread of a disease caused by particulate infective material is not diminished by isolation of infective persons and by destruction of the infective particles, and to suppose further, that the occasional occurrence of " return" cases is more than a small drawback to the good achieved by isolation hospitals, is to strain the facts and to arrive at a conclusion which is contradicted by our general knowledge of the causation of specific febrile diseases.

\section{Duration of Smallpox Immunity at Pekin.}

Dr. Matignon, ${ }^{2}$ in a communication to the Academy of Medicine, stated the fact that an attack of smallpox in Northern China confers a temporary immunity lasting from seven to nine years. He also says that among Chinese vaccinated children the ratio of success is $79.5 \%$ at twelve years of age, $77 \%$ at ten years, and $53.3 \%$ at eight years, since the majority of children have probably, if not certainly, had smallpox in their early childhood. He has seen 3 positive cases of smallpox occurring a second time in the same person, the victims being two Frenchmen and one Swiss, and while it is proper to take account of the diminution of resistance caused by the fatigue of a long voyage, the severity of the weather, etc., he says the real cause is to be found in the widespread prevalence of smallpox at Pekin. At the beginning of spring, one may see upon the streets everywhere Chinese with their faces and hands covered with variolous crusts in a condition of desquamation, at the same time selling embroidery, trinkets, etc. He urges the importance of revaccination immediately upon arriving in China.

\section{Prevention of Tuberculosis.}

Dr. Thompson, ${ }^{8}$ of New South Wales, proposes the following measures for the prevention of tuberculosis: (1) Notification and registration of phthisis. Such registration to be confidential; (2) free examination of sputa; (3) disinfection of rooms obligatory after death or removal of consumptive patients; (4) local registrars to notify every death from phthisis to the health authority as soon as received by them; (5) enforcement of good building laws.

\section{Existence of Tuberculosis at Different Ages.}

Nägeli ${ }^{4}$ found at the Pathological Institute of Zurich, as the result of 500 autopsies, no traces of tubercle in 16 infants under one year old, 12 of whom were new born. From two to five years it is rare, but fatal when it occurs. From five to

2 La mèd. mod., November 7, 1900, p. 522. 3 Public Health, January, 1900, p. 248.

4 Hyg. Rundsch., 2, 1901 . 